\title{
Pretreatment with glucose-insulin-potassium improves ventricular performances after coronary artery bypass surgery: a randomized controlled trial
}

\author{
Marc Licker $^{1,2} \oplus \cdot$ Thomas Reynaud $^{1} \cdot$ Najia Garofano $^{1} \cdot$ Tornike Sologashvili $^{3} \cdot$ John Diaper $^{1} \cdot$ Christoph Ellenberger $^{1}$
}

Received: 8 September 2018 / Accepted: 12 February 2019 / Published online: 20 February 2019

(c) Springer Nature B.V. 2019

\begin{abstract}
Heart failure is the main cause of poor outcome following open heart surgery and experimental studies have demonstrated that glucose-insulin-potassium (GIK) infusion exerts cardioprotective effects by reducing myocardial ischemia-reperfusion injuries. This randomized controlled trial was designed to assess the effects of GIK on left ventricular function in moderateto-high risk patients undergoing on-pump isolated coronary artery bypass surgery (CABGS), or combined with aortic valve replacement. The primary outcomes were the effects of GIK on two- and three-dimensional left ventricular ejection fraction (2D and 3D-LVEF), and on transmitral flow propagation velocity $(\mathrm{Vp})$, that occurred between the pre- and post-CPB periods. GIK administration was associated with favorable interaction effects $(p<0.001)$ on 2D-LVEF, 3D-LVEF and Vp changes over the study periods. In GIK pretreated patients $(\mathrm{N}=54), 2-\mathrm{D}$ and 3D-LVEF and Vp increased slightly during surgery (mean difference $[\mathrm{MD}]+3.5 \%, 95 \%$ confidence interval $[95 \% \mathrm{CI}]-0.2$ to $7.1 \%, \mathrm{MD}+4.0 \%, 95 \% \mathrm{CI} 0.6-7.4 \%$, and $\mathrm{MD}+22.2 \%, 95 \% \mathrm{CI} 16.0-28.4 \%$, respectively). In contrast, in the Placebo group ( $\mathrm{N}=46), 2 \mathrm{D}$-and 3D-LVEF, as well as Vp all decreased after CPB (MD - 7.5\% [ -11.6 to - 3.4\%], MD - 12.0\% [ -15.2 to $-8.8 \%$ ] and MD - 21.3\% [-25.7 to $-16.9 \%$, respectively). In conclusion, the administration of GIK resulted in better preservation of systolic and diastolic ventricular function in the early period following weaning from CPB.
\end{abstract}

Keywords Peri-operative insulin $\cdot$ Effects $\cdot$ Cardiopulmonary bypass management $\cdot$ TEE $\cdot$ Diagnosis $\cdot$ Hypotension $\cdot$ LV failure $\cdot$ Diagnosis and treatment post-CPB

\section{Introduction}

Currently, cardiovascular diseases remain the leading causes of morbidity and mortality in the developed world [1]. Despite progress in medical treatment to control

This paper was presented at the annual meeting of the European Society of Anesthesiology in Copenhagen, June 4, 2018.

Marc Licker

marc-joseph.licker@hcuge.ch

Thomas Reynaud

thomas.reynaud@hcuge.ch

Najia Garofano

najia.garofano@hcuge.ch

Tornike Sologashvili

tornike.sologashvili@hcuge.ch

John Diaper

john.diaper@hcuge.ch cardiovascular risk factors and stabilize the atheromatous plaque, a large number of patients still require myocardial revascularization procedures, with a major shift over the last two decades from coronary artery bypass graft surgery (CABGS) to percutaneous angioplasty intervention (PCI) as the revascularization of choice [2,3]. Importantly, the proportion of high-risk patients undergoing CABGS has increased owing to the ageing population and the rising

Christoph Ellenberger

christoph.ellenberger@hcuge.ch

1 Department of Anaesthesiology, Pharmacology and Intensive Care, University Hospital of Geneva, Rue Gabrielle-Perret-Gentil 4, 1211 Geneva, Switzerland

2 Faculty of Medicine, University of Geneva, Geneva, Switzerland

3 Division of Cardiovascular Surgery, University Hospital of Geneva, Geneva, Switzerland 
prevalence of associated comorbidities such as diabetes mellitus and heart failure [2, 4].

On-pump cardiac surgery is associated with predictable myocardial ischaemia-reperfusion damages that parallel the duration of aortic cross-clamping and are greater in the higher risk surgical population presenting with left ventricular hypertrophy, endothelial dysfunction and severe coronary artery disease [5]. The consequent post-cardiotomy ventricular dysfunction often requires temporary inotropic support and may result in low cardiac output syndrome that has been incriminated in early mortality and poor quality of life $[6,7]$.

For more than four decades, the Holy Grail in cardiac surgery has been focused in numerous cardioprotective strategies founded on well-reasoned pathophysiological mechanisms, namely hypothermic cardiac arrest with potassiumenriched solutions as well as ischemic, pharmacological and anaesthetic pre (and post) conditioning [8]. Nowadays, the infusion of cold blood or crystalloid solutions through the aortic root or selectively into coronary arteries has become a standard of care to minimize myocardial injuries during open heart surgery [9]. So far, novel strategies, such as remote or direct ischemic myocardial preconditioning have failed to provide convincing clinical results [10].

Since its introduction in 1962 in the setting of ischemic heart diseases, the administration of glucose-insulin-potassium (GIK) has long been advocated to enhance myocardial protection in cardiac surgery [11]. Experimental studies strongly support the cardioprotective effects of glucose-insulin-potassium (GIK) through metabolic modulation as well as antiapoptotic, anti-inflammatory and antioxidant effects [12]. In patients undergoing CABGS, although GIK infusion has been associated with improved cardiac output and fewer episodes of atrial fibrillation [13], data regarding clinical outcomes remain controversial and, patients with poor ventricular function who might benefit from a cardioprotective strategy have been excluded in most of these studies [14]. Moreover, no study has been focused on the quantitative assessment of left ventricular (LV) function using transesophageal echocardiography (TEE).
Considering the potential cardioprotective effects of insulin, the current study was aimed to investigate the effects of GIK infusion on left ventricular systolic and diastolic function in moderate-to-high risk patients undergoing on-pump CABGS and receiving standard cardioprotective techniques.

\section{Methods}

This single-centre, randomized parallel group, superiority trial was approved by the institutional review board at the University Hospital of Geneva (CER: 08-095) and written consent was obtained from each eligible participant. From January 1, 2009 to December 31, 2013, adult patients scheduled for elective CABGS,--isolated or combined with aortic valve replacement (AVR) - , were screened and enrolled if they had a Bernstein-Parsonnet score higher than 7. Exclusion criteria consisted in poorly controlled diabetes mellitus, severe liver disease (Child-Pugh C stage), dementia or significant cerebrovascular disease as well as any contraindications for inserting a transoesophageal echocardiographic (TEE) probe. Results regarding clinical outcome and the occurrence of post-cardiotomy ventricular dysfunction (PCVD) in the whole study population $(\mathrm{N}=212)$ have been reported previously [15]. In the current investigation and, as pre-planned (ClinicalTrial.gov NCT00788242), we focused on a subset of patients who underwent CABG surgery with or without AVR (with severe aortic stenosis) and, in whom TEE examination was completed with good quality imaging.

Patients were randomized to receive coded solutions of saline ( $\mathrm{NaCl} 0.9 \%$, Placebo group) or GIK (human Actrapid, Novo Nordisk $20 \mathrm{IU}$ and potassium chloride $10 \mathrm{mEq}$ in $50 \mathrm{~mL}$ of $40 \%$ glucose, GIK group) over $60 \mathrm{~min}$ upon anaesthetic induction (Fig. 1). Randomization (1:1) was generated with a computer program and stratified based on Bernstein Parsonnet score $\leq 15$ or $>15$, with permuted blocks of four patients. Study drug codes were stored in sealed envelopes and saline/GIK solutions were prepared by an anaesthesia nurse not involved in perioperative patient management nor in data recordings. Blood glucose concentration (BGC)

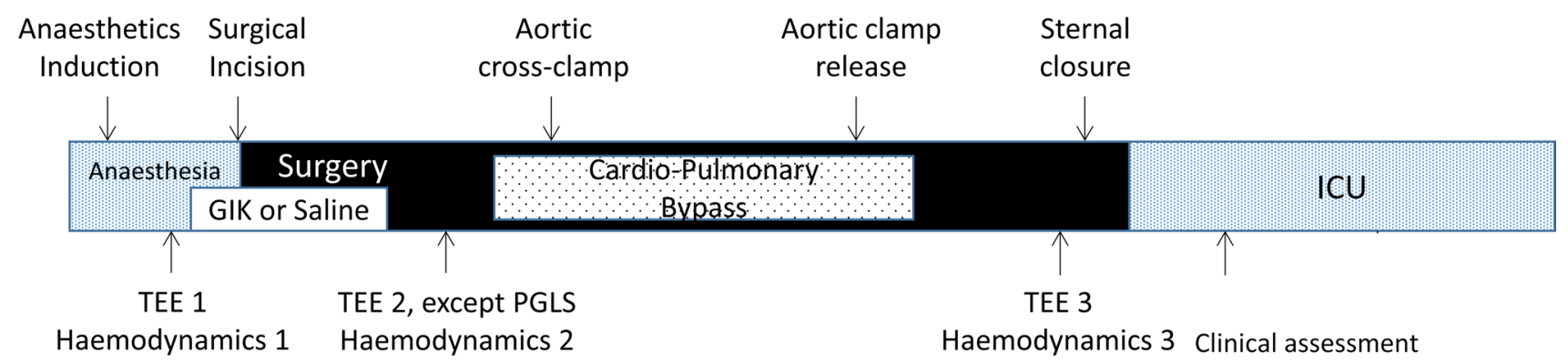

Fig. 1 Time line of the research protocol with study interventions and data collection. GIK glucose-insulin-potassium, ICU intensive care unit, $P G L S$ peak global longitudinal strain, $P O D$ postoperative day, TEE transesophageal echocardiography 
were measured every $30 \mathrm{~min}$ and insulin and glucose (40\% solution) were administered intravenously to maintain BGC between 4.5 and $10 \mathrm{mM} / \mathrm{L}$ throughout surgery. Anaesthesiologists, echocardiographers, surgeons and intensivists were blinded to group allocation as well as the two research assistants who separately collected pre- and intraoperative data as well as postoperative clinical outcome data.

The standard anaesthetic technique consisted in intravenous administration of propofol and ketamine that was combined with intrathecal morphine analgesia $(5-10 \mathrm{mcg} /$ $\mathrm{kg}$ ) to minimize the administration of opiates and to facilitate early extubation. Inhaled sevoflurane (1-1.5 MAC) was administered in all patients over at least $30 \mathrm{~min}$ before the start of CPB as a mean to enhance myocardial protection [16]. All cardiac surgical procedures were performed via sternotomy, under normothermic nonpulsatile $\mathrm{CPB}$ with the circuit and membrane oxygenator primed with $1.5-2 \mathrm{~L}$ of fluids (1L Ringer-Acetate and $0.5-1 \mathrm{~L}$ of hydroxyethyl starch $6 \%$ 130/0.4). After aortic cross-clamping, cold blood cardioplegia was periodically infused in the aortic root to ensure myocardial protection and $250 \mathrm{~mL}$ of normothermic perfusate was given prior to aortic declamping.

Weaning from CPB was guided by TEE and hemodynamic measurements [17]. Inotropes (dobutamine, epinephrine, milrinone) were initiated in the presence of new/worsening ventricular dysfunction and low MAP $(<70 \mathrm{mmHg})$ that was not responsive to fluid loading and/or vasopressor therapy. Conversely, the decision to withdraw inotropic support was taken if the hemodynamic condition improved steadily.

The primary outcome variables were the left ventricular ejection fraction (LVEF) as measured by two- and three dimensional (2D and 3D) echocardiography as well as the transmitral flow propagation velocity $(\mathrm{Vp})$. Secondary study endpoints included other TEE parameters, the occurrence of PCVD, any postoperative complications (modified Dindo-Clavien classification, grade $\geq 2$ ) and peak troponin-I plasma concentrations.

Using a multiplane TEE probe with an iE33 ultrasound system (Philips Medical System, Eindhoven, Netherland), intraoperative imaging was performed at three time points, before drug infusion, 20 min after drug infusion and at the end of surgery (Fig. 1). Cine loops were obtained by two TEE experts from standard mid-esophageal four- and two-chamber (4C and 2C) views and transgastric midpapillary short-axis views. All cine loops were stored on an external hard disc and used for evaluations if they corresponded to the appropriate standard views [18]. The papillary muscles were included in the volumes or areas. In the mid-esophageal $4 \mathrm{C}$ and $2 \mathrm{C}$ views, the $\mathrm{LV}$ endocardial borders in end-diastole and end-systole were automatically detected using the preinstalled software based on a geometric model of the LV consisting of 20 circular or ellipsoid columns (biplane Simpson's method of disks). After manual adjustment of the endocardial border, the end-diastolic and end-systolic volume (ESV and EDV) were measured and the LVEF was calculated (LVEF = $[\mathrm{EDV}-\mathrm{ESV}] / \mathrm{EDV})$. The transgastric mid-papillary shortaxis view served to manually trace the end-diastolic area and end-systolic area (EDA and ESA) and to calculate the fractional area change (LVFAC $=[E D A-E S A] / E D A)$. From M-mode recordings, the posterior wall thickness (PWT) was measured at end-diastole.

After acquiring a full volume scan of the left ventricle from $4 \mathrm{R}$-wave triggered sub-volumes, real-time 3D data sets were analysed with the QLAB 3D-advanced quantification software package to measure LV volume and compute 3D-LVEF. Using tissue Doppler imaging (TDI), early and late myocardial diastolic velocities ( $\mathrm{e}^{\prime}$ and $\mathrm{Am}$ ) were measured and the E/e' ratios were calculated. To determine the transmitral flow propagation velocity $(\mathrm{Vp})$, the color M-mode was used in the mid-esophageal 4-chamber view by adjusting the Nyquist limit and baseline shift. Speckletracking analysis was performed using the cardiac motion quantification software (CMQ-Advanced; Philips Healthcare, Eindhoven, Netherland) before drug administration and at the end of surgery. Two consecutive ECG-gated cardiac cycles were acquired on the three longitudinal apical views $(4 \mathrm{CH}, 3 \mathrm{CH}$ and $2 \mathrm{CH})$ at a frame rate of $40-80 \mathrm{~Hz}$ and stored digitally and, peak global longitudinal strain (PGLS) was calculated as the mean of all strain values from basal, midpapillary and apical segments. Diastolic dysfunction was diagnosed and graded according to the American Society for Echocardiography (ASE) recommendations (normal, impaired relaxation, pseudo-normalization and restrictive pattern) [19].

At least 30 patients per group are required to detect LVEF changes over 3 measurements in the Placebo group and in the GIK group resulting in a between-group difference of $5 \%$ (assuming a variance of 64 at each measurement, a correlation of 0.7 between the repeated measurements, a power of 0.8 , and a type I error of 0.05 ). This power calculation is independent from the baseline value of LVEF.

Summary descriptive statistics are expressed as frequencies (and percentages, \%), medians (and interquartile range, IQR 25-75\%), means (and standard deviations, SD; 95\% confidence intervals, CI) and risk ratios (RR and 95\% confidence interval, 95\% CI). Pearson's correlation coefficient was used to assess the inter- and intra-observer variability of the TEE measurements in randomly selected patients $(n=10)$. To analyze differences between the two groups, two-sided unpaired t tests, Wilcoxon rank-sum tests, or chisquared tests were used where appropriate. Repeated-measures two-way analysis of variance (ANOVA) with Greenhouse-Geisser correction was used to estimate between and within group differences. Statistical tests were conducted 
using STATA 14 software (Stata Corp, College Station, TX, USA).

\section{Results}

From a total of 295 screened patients, 224 were randomized into GIK and Placebo groups (110 and 112, respectively). Among those undergoing CABG surgery or CABG surgery associated with AVR, 49 were allocated to the Placebo group and 66 to the GIK group (Fig. 2). After exclusion of cases with unavailability to perform TEE or poor quality imaging $(\mathrm{N}=15), 100$ patients remained for final analysis, 46 in the Placebo group and 54 in the GIK group.

As shown in Table 1, baseline preoperative clinical and biological variables were well balanced in the two groups, except for a lower LVEF in the GIK group. Intraoperative surgical characteristics, blood glucose concentrations and supplemental administration of insulin and glucose did not differ between the two groups.

Intra- and interobserver variabilities were good to excellent for 2D-LVEF, 3D-LVEF and PGLS and, intermediate values were achieved for $\mathrm{Vp}$ as assessed by Pearson coefficients (Table 2).

At preoperative baseline, LVFAC, 2D-LVEF, 3D-LVEF and $\mathrm{Vp}$ were slightly lower in the GIK group compared with the Placebo group (Table 3).

The administration of GIK was associated with strong interaction effects on LVFAC, 2D-LVEF, 3D-LVEF and $V p$ throughout the study periods $(\mathrm{p}<0.001$ for all four TEE parameters; Table 3; Fig. 3 and Appendix). Before starting $\mathrm{CPB}$, GIK infusion was associated with a mean increase of $7.7 \%$ in LVFAC (95\% CI 2.6 to $12.9 \%$ ), $2.0 \%$ in 2D-LVEF

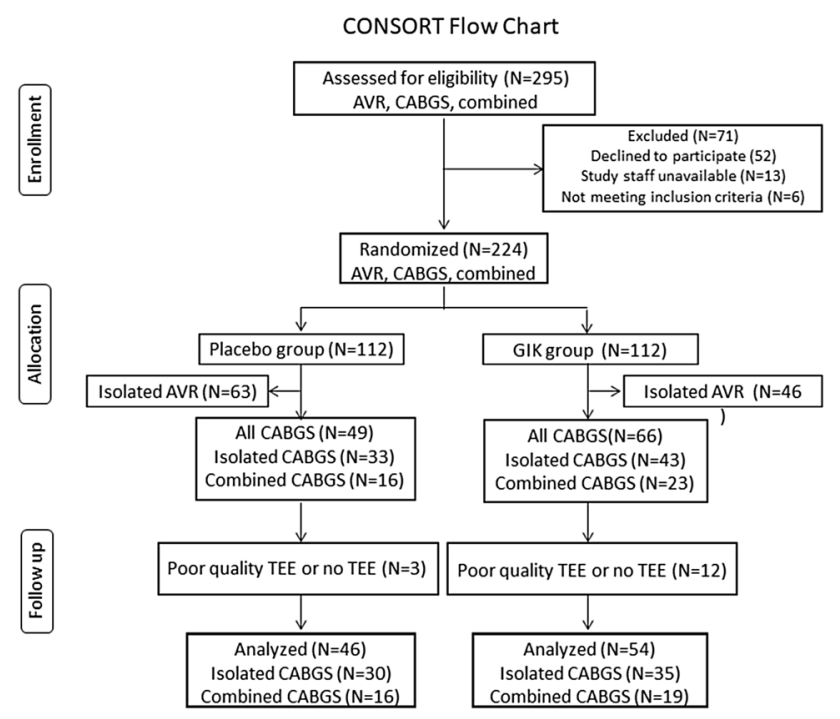

Fig. 2 Consolidated Standards of Reporting Trials flow diagram
(95\% CI -0.5 to $4.5 \%$ ), 3.8\% in 3D-LVEF (95\% CI 1.6 to $5.9 \%$ ), and $13 \%$ in $\mathrm{Vp}$ (95\% CI 9.4 to $16.2 \%$ ). After weaning from CPB and compared to baseline, LVFAC increased by $8.0 \%$ (95\% CI 3.4 to $12.7 \%$ ), 2D-LVEF by $3.5 \%$ (95\% CI -0.2 to $7.1 \%$ ), 3D-LVEF by $4.0 \%$ (95\% CI 0.6 to $7.4 \%$ ), and $\mathrm{Vp}$ by $22.2 \%$ (95\% CI 16.0 to $28.4 \%$ ), in the GIK group. In contrast, patients in the Placebo group exhibited reductions in LVFAC (mean difference [MD] $-14.6 \%, 95 \% \mathrm{CI}$ -19.2 to $-10.0 \%$ ), in 2D-LVEF (MD $-7.5 \%, 95 \% \mathrm{CI}$ -11.6 to $-3.4 \%$ ), in 3D-LVEF (MD - $12.0 \%, 95 \%$ CI -15.2 to $-8.8 \%$ ), and in $\mathrm{Vp}$ (MD $-21.3 \%, 95 \% \mathrm{CI}-25.7$ to $-16.9 \%)$.

The administration of GIK was also associated with strong interaction effects on PGLS, LV systolic strain rate, and the $E / \mathrm{e}^{\prime}$ ratio $(\mathrm{p}=0.007, \mathrm{p}=0.008$, respectively $\mathrm{p}=0.001)$. In the two groups, changes in TEE parameters did not differ among patients undergoing isolated CABGS compared with those undergoing CABGS combined with AVR.

Regarding clinical outcome, GIK pretreatment was associated with a reduction in respiratory complications (RR $0.62,95 \%$ CI 0.44 to 0.88 ) and in PCVD (RR 0.25, 95\% CI 0.09 to 0.63 ) along with lesser requirements for norepinephrine (30 [55.6\%] vs. 36 [78.3\%], in the Placebo group, $\mathrm{p}=0.017)$, dobutamine $(18$ [33.3\%] vs. 30 [65.2\%] in the Placebo group, $\mathrm{p}=0.001$ ), or a combination of at least two inotropes (17 [31.5\%] vs. 28 [60.9\%] in the Placebo group, $\mathrm{p}=0.003$ ). In-hospital mortality, the incidence of cardiovascular complications and renal dysfunction, as well as peak levels of cardiac troponin-I did not differ between the two groups (Table 5 in Appendix).

\section{Discussion}

The optimal protection of the myocardium during on-pump cardiac surgery remains a challenge and it markedly impacts clinical outcome after myocardial revascularization and valvular surgery [7, 21]. In this RCT including moderate-tohigh risk patients undergoing isolated or combined CABGS, GIK infusion resulted in immediate improvement in systolic and diastolic LV function and it prevented the impairment of LV function that was observed early after weaning from $\mathrm{CPB}$ in patients receiving the standard cardioprotective technique. Moreover, GIK pre-treatment was associated with lesser need for cardiovascular drug support, fewer respiratory complications and shorter ICU length of stay.

In previous clinical trials conducted in CABGS, patients with poor ventricular function were often excluded and therefore, functional benefit could not be demonstrated given the lower patient risk characteristics [14]. In the present trial, the moderate-to-elevated risk profile was mainly related to advanced age (60\% older than 70 years) and a 
Table 1 Characteristics of patients undergoing coronary artery bypass grafting and receiving Placebo or glucoseinsulin potassium (GIK) infusion

\begin{tabular}{|c|c|c|c|}
\hline Characteristics & $\begin{array}{l}\text { Placebo } \\
(\mathrm{N}=46)\end{array}$ & $\begin{array}{l}\text { GIK } \\
(\mathrm{N}=54)\end{array}$ & $\mathrm{p}$ value \\
\hline \multicolumn{4}{|l|}{ Demographics } \\
\hline Age, years ${ }^{\mathrm{a}}$ & $69.3(11.0)$ & $71.8(8.4)$ & $0.266^{\dagger}$ \\
\hline Body mass index ${ }^{a}$ & $26.4(4.2)$ & $28.7(4.6)$ & $0.021^{\dagger}$ \\
\hline Sex, male & $40(87.0)$ & $41(75.9)$ & $0.161^{\ddagger}$ \\
\hline \multicolumn{4}{|l|}{ Comorbidities } \\
\hline Bernstein-Parsonnet score ${ }^{\mathrm{a}}$ & $20.5(8.8)$ & $21.8(8.6)$ & $0.459^{\dagger}$ \\
\hline Hypertension & $41(89.1)$ & $53(98.2)$ & $0.058^{\ddagger}$ \\
\hline Pulmonary hypertension & $3(6.5)$ & $7(13.0)$ & $0.335^{\ddagger}$ \\
\hline Hypercholesterolemia & $37(80.4)$ & $51(94.4)$ & $0.032^{\ddagger}$ \\
\hline Diabetes mellitus & $18(38.1)$ & $29(53.7)$ & $0.146^{\ddagger}$ \\
\hline Vascular disease & $20(43.5)$ & $23(42.6)$ & 0.929 \\
\hline Chronic obstructive pulmonary disease & $8(17.4)$ & $9(16.7)$ & $0.923^{\ddagger}$ \\
\hline Heart failure NYHA III/IV & $15(32.7)$ & $20(37.0)$ & $0.679^{\ddagger}$ \\
\hline Left ventricular ejection fraction ${ }^{\mathrm{b}}, \%$ & $44(4.5)$ & $41(2.9)$ & $0.036^{\dagger}$ \\
\hline Left ventricular wall thickness ${ }^{\mathrm{b}}, \mathrm{mm}$ & $1.12(0.20)$ & $1.15(0.16)$ & $0.514^{\dagger}$ \\
\hline Previous cardiac surgery & $8(8.7)$ & $14(13.0)$ & $0.541^{\ddagger}$ \\
\hline \multicolumn{4}{|l|}{ Chronic treatment } \\
\hline Beta-blockers & $34(74)$ & $35(65)$ & $0.389^{\ddagger}$ \\
\hline Calcium-channel antagonists & $9(19.6)$ & $14(25.9)$ & $0.633^{\ddagger}$ \\
\hline ACEI/AII antagonists & $24(52.2)$ & $25(45.4)$ & $0.688^{\ddagger}$ \\
\hline Diuretics & $22(39.3)$ & $23(42.6)$ & $0.688^{\ddagger}$ \\
\hline \multicolumn{4}{|l|}{ Blood parameters } \\
\hline Hemoglobin, $\mathrm{g} / \mathrm{dL}^{\mathrm{a}}$ & $11.8(1.9)$ & $11.9(2.4)$ & 0.811 \\
\hline Creatinine clearance, $\mathrm{mL} / \mathrm{min}^{\mathrm{a}}$ & $80.3(45.5)$ & $74.8(30.5)$ & 0.477 \\
\hline \multicolumn{4}{|l|}{ Surgical characteristics } \\
\hline CABG with AVR & $16(34.8)$ & $17(31.5)$ & $0.726^{\ddagger}$ \\
\hline Number of coronary grafts & $3(1-5)$ & $3(1-4)$ & 0.859 \\
\hline Aortic clamping time, $\min ^{\mathrm{a}}$ & $74.1(31.9)$ & $81.2(38.1)$ & $0.323^{\dagger}$ \\
\hline Fluids, $\mathrm{mL}^{\mathrm{a}}$ & 2927 (977) & $3330(1810)$ & $0.180^{\dagger}$ \\
\hline Blood transfusion & $31(67.4)$ & $39(72.2)$ & 0.599 \\
\hline Fresh frozen plasma & $15(32.6)$ & $16(29.6)$ & $0.748^{\ddagger}$ \\
\hline Platelets & $8(17.4)$ & $11(20.4)$ & $0.705^{\ddagger}$ \\
\hline \multicolumn{4}{|l|}{ Blood glucose (mMol/L) } \\
\hline Start of surgery ${ }^{a}$ & $6.7(1.5)$ & $7.3(2.1)$ & $0.166^{\dagger}$ \\
\hline Before bypass ${ }^{\mathrm{a}}$ & $7.6(1.3)$ & $7.8(3.0)$ & $0.680^{\dagger}$ \\
\hline During bypass $^{\mathrm{a}}$ & $8.0(1.8)$ & $7.6(2.8)$ & $0.493^{\dagger}$ \\
\hline End of surgery ${ }^{a}$ & $7.9(1.2)$ & $7.3(1.9)$ & $0.101^{\dagger}$ \\
\hline Supplemental insulin & $10(21.4)$ & $19(35.2)$ & $0.140^{\ddagger}$ \\
\hline Supplemental glucose infusion & $1(2.2)$ & $5(9.3)$ & $0.214^{\ddagger}$ \\
\hline
\end{tabular}

Data given as number of patients (percentage) unless otherwise indicated

$A C E I$ angiotensin converting enzyme inhibitors, $A I I$ angiotensin II, $A V R$ aortic valve replacement, $C A B G$ coronary artery bypass grafting, $C P B$ cardiopulmonary bypass, $L V E F$ left ventricular ejection fraction

Chi-squared tests were used for statistical tests unless otherwise indicated; ${ }^{\dagger}$ Student $\mathrm{t}$ test; ${ }^{\dagger}$ Fisher exact test ${ }^{\text {a }}$ Data given as mean (standard deviation) or median (range)

${ }^{\mathrm{b}}$ Transthoracic echocardiography performed the day before surgery high prevalence of comorbidities (hypertension in 93\% of patients, vascular disease in $43 \%$, heart failure in 35\%, diabetes mellitus in $28 \%$ and aortic valve stenosis in $33 \%$ ). With a mean Parsonnet score of 21, the expected mortality was $5.5 \%$ [22]. The lower observed mortality (4.0\%) was partly attributed to standardization of perioperative anaesthetic 
Table 2 Interobserver and intraobserver variability for measurements of transoesophageal echocardiographic data

\begin{tabular}{lllll}
\hline Measurements & $\begin{array}{l}\text { Interobserver } \\
\text { correlation coef- } \\
\text { ficient }\end{array}$ & $95 \%$ confidence interval & $\begin{array}{l}\text { Intraobserver } \\
\text { correlation coef- } \\
\text { ficient }\end{array}$ & 95\% confidence interval \\
\hline 2D-LVEF & 0.910 & $0.742-0.966$ & 0.903 & $0.802-0.955$ \\
3D-LVEF & 0.832 & $0.621-0.946$ & 0.870 & $0.615-0.988$ \\
PGLS & 0.876 & $0.579-0.928$ & 0.879 & $0.661-0.922$ \\
Vp & 0.762 & $0.538-0.955$ & 0.811 & $0.507-0.954$ \\
\hline
\end{tabular}

$2 D-L V E F$ two-dimensional left ventricular ejection fraction, $3 D-L V E F$ three-dimensional left ventricular ejection fraction, $P G L S$ peak global longitudinal strain, $V p$ transmitral flow propagation velocity and surgical processes including the goal-directed approach based on TEE and hemodynamic monitoring [23].

To assess the intraoperative changes in LV function, we used 2D and 3D-TEE as well as speckle tracking imaging. Some limitations of standard 2D-imaging (e.g., geometric assumptions, foreshortenings and difficulties in proper delineation of the endocardial LV borders) were partly overcome by $3 \mathrm{D}$ echocardiography that has demonstrated excellent agreement with magnetic resonance imaging, the reference method for assessing LV function [24, 25]. Analysis of myocardial deformation based on velocity gradients measured by displacement of speckles from 2D images is another method to quantify longitudinal LV shortening that has been shown particularly valuable in patients with heart failure [26].

During the pre-ischemic period, TEE indicators of systolic and diastolic function (2D-, 3D-LVEF and Vp) slightly decreased in the Placebo group as a result of the cardiodepressive effects of anesthetic agents $[27,28]$ whereas these parameters remained unchanged or increased after the infusion of GIK. In brain death-induced heart failure, GIK infusion has been shown to increase LVEF as much as moderate doses of dobutamine while avoiding tachyarrhythmias and arterial hypotension [29]. Likewise in patients with severe coronary artery disease, GIK infusion at a similar dosage has been shown to increase the ischemic threshold and LVEF while improving exercise tolerance and correcting stressinduced LV dysfunction [30, 31].

In the present protocol, the administration of insulin at a rate of 4 to $6 \mathrm{mU} / \mathrm{kg} / \mathrm{min}$ was expected to achieve plasma insulin concentrations in the range of 3 to $4 \mathrm{nmol} / \mathrm{L}$ (equivalent to 0.4 to $0.5 \mathrm{IU} / \mathrm{L}$ ), these levels being necessary to provide short-term enhancement of ventricular performances and cardioprotective effects [32].

Several mechanisms are responsible for GIK-induced enhancement of ventricular contractility at lesser oxygen demand. First, in isolated cardiac muscle preparations, insulin exerts concentration-dependent positive inotropic effects after coupling to specific membrane receptors and subsequent stimulation of calcium ATPase activity, sodium/ calcium exchange activity as well as calcium current in L-type channel [33]. Second, sensitization and increase in beta-1 adrenergic receptors may further enhance myoplasmic calcium availability by increasing cyclic adenosine monophosphate substrates [34, 35]. Third, GIK has been shown to suppress the surgically-induced inflammatory response, as reflected by reduced levels of C-reactive protein, tumor necrosis factor-alpha and interleukin- 6 that are implicated in cardiac contractile dysfunction [36]. Finally, in GIK treated hearts, the increased glucose uptake coupled with decreased free fatty acid (FFA) uptake, results in a shift from FFA to glucose aerobic metabolism and more efficient oxygen utilization, with larger amounts of ATP being generated per oxygen mole and directly available for excitation-contraction coupling within the cardiomyocytes [37]. Contrasting with the immediate response to beta-adrenergic receptor agonists, the maximal positive inotropic effects has been shown to occur 20 to 40 min after GIK infusion and this delayed response lend support to a predominant metabolic effect of the GIK [38].

After weaning from CPB and compared with pre-bypass conditions, the Placebo group exhibited a significant decline in both LV systolic and diastolic function that required the administration of inotropes in two-third of patients. Although inotropic support may transiently enhance postischemic recovery and facilitate weaning from $\mathrm{CPB}$, it has been identified as a strong predictor of increased mortality and cardiovascular complications in cardiac surgery, possibly resulting from increased oxygen consumption, exhaustion of energetic substrates and beta-adrenergic desensitization within the myocardium [6].

In contrast, in GIK pretreated patients, echocardiographic markers of LV systolic function were well preserved compared with preoperative baseline, LV diastolic function was even improved and therefore, only a third of these patients required inotropic support following CPB. Mitigation of the contractile dysfunction with GIK pretreatment may result from optimization of cardiac metabolism and promotion of cardiomyocyte survival pathways before the onset of 
Table 3 Echocardiographic parameters in patients undergoing coronary artery bypass grafting and receiving Placebo or glucose-insulin potassium (GIK) infusion

\begin{tabular}{|c|c|c|c|c|}
\hline Parameter & Start surgery & After GIK & End surgery & p-value \\
\hline \multicolumn{5}{|l|}{ Preload } \\
\hline \multicolumn{5}{|c|}{ End diastolic area $\left(\mathrm{cm}^{2}\right)$} \\
\hline All patients & $13.6(2.7)$ & $13.1(2.7)$ & $12.9(3.1)$ & 0.002 \\
\hline Placebo group & $13.7(2.3)$ & $13.2(2.4)$ & $13.0(3.0)$ & $<0.036$ \\
\hline \multirow[t]{2}{*}{ GIK group } & $13.6(3.0)$ & $13.1(2.9)$ & $12.8(3.3)$ & $<0.038$ \\
\hline & & Effect modification by GIK & & 0.953 \\
\hline \multicolumn{5}{|l|}{ Systolic function } \\
\hline \multicolumn{5}{|l|}{ LV FAC (\%) } \\
\hline All patients & $43.2(8.7)$ & $42.8(9.9)$ & $41.8(9.6)$ & 0.278 \\
\hline Placebo group & $46.2(7.4)$ & $41.8(8.8)$ & $39.4(9.8)$ & $<0.001$ \\
\hline \multirow[t]{2}{*}{ GIK group } & $40.6(9.0)$ & $43.7(10.8)$ & $43.9(9.1)$ & 0.006 \\
\hline & & Effect modification by GIK & & $<0.001$ \\
\hline \multicolumn{5}{|l|}{ 3D-LVEF (\%) } \\
\hline All patients & $44.2(6.9)$ & $43.9(6.4)$ & $42.6(7.0)$ & 0.007 \\
\hline Placebo group & $46.8(6.6)$ & $44.2(6.7)$ & $41.1(7.5)$ & $<0.001$ \\
\hline \multirow[t]{2}{*}{ GIK group } & $42.1(6.4)$ & $43.7(6.2)$ & $43.8(5.7)$ & 0.017 \\
\hline & & Effect modification by GIK & & $<0.001$ \\
\hline \multicolumn{5}{|l|}{ 2D-LVEF $(\%)$} \\
\hline All patients & $41.4(6.0)$ & $40.9(6.2)$ & $40.7(7.2)$ & 0.315 \\
\hline Placebo group & $42.5(5.3)$ & $40.4(6.0)$ & $39.3(8.3)$ & $<0.001$ \\
\hline \multirow[t]{2}{*}{ GIK group } & $40.5(6.4)$ & $41.3(6.4)$ & $41.9(5.9)$ & 0.093 \\
\hline & & Effect modification by GIK & & $<0.001$ \\
\hline \multicolumn{5}{|l|}{ PGLS (\%) } \\
\hline All patients & $-12.3(2.6)$ & - & $-11.2(2.4)$ & 0.002 \\
\hline Placebo group & $-13.1(2.2)$ & - & $-11.3(2.7)$ & $<0.001$ \\
\hline \multirow[t]{2}{*}{ GIK group } & $-11.5(2.5)$ & - & $-11.2(2.1)$ & 0.369 \\
\hline & & Effect modification by GIK & & $<0.007$ \\
\hline \multicolumn{5}{|c|}{ LV systolic strain rate $\left(\mathrm{s}^{-1}\right)$} \\
\hline All patients & $-1.03(0.28)$ & - & $-0.99(0.24)$ & 0.124 \\
\hline Placebo group & $-1.12(0.28)$ & - & $-1.01(0.26)$ & 0.007 \\
\hline \multirow[t]{2}{*}{ GIK group } & $-0.94(0.26)$ & - & $-0.97(0.23)$ & 0.396 \\
\hline & & Effect modification by GIK & & 0.008 \\
\hline \multicolumn{5}{|l|}{ Diastolic function } \\
\hline \multicolumn{5}{|c|}{ Transmitral E/A ratio } \\
\hline All patients & $1.19(0.65)$ & $1.15(0.50)$ & $1.19(0.49)$ & 0.593 \\
\hline Placebo group & $1.24(0.62)$ & $1.11(0.46)$ & $1.00(0.48)$ & 0.001 \\
\hline \multirow[t]{2}{*}{ GIK group } & $1.14(0.67)$ & $1.18(0.54)$ & $1.34(0.46)$ & 0.021 \\
\hline & & Effect modification by GIK & & $<0.001$ \\
\hline \multicolumn{5}{|c|}{ Isovolemic relaxation time (ms) } \\
\hline All patients & $82.2(37.7)$ & $84.9(35.7)$ & $85.0(33.7)$ & 0.361 \\
\hline Placebo group & $88.5(35.5)$ & $88.8(36.5)$ & $86.9(34.7)$ & 0.729 \\
\hline \multirow[t]{2}{*}{ GIK group } & $76.9(39.0)$ & $81.6(35.0)$ & $83.4(33.1)$ & 0.140 \\
\hline & & Effect modification by GIK & & 0.218 \\
\hline \multicolumn{5}{|c|}{ Pulmonary venous $S / D$ ratio } \\
\hline All patients & $1.34(0.55)$ & $1.38(0.52)$ & $1.42(0.47)$ & 0.025 \\
\hline Placebo group & $1.26(0.49)$ & $1.31(0.52)$ & $1.35(0.48)$ & 0.311 \\
\hline \multirow[t]{2}{*}{ GIK group } & $1.42(0.62)$ & $1.44(0.52)$ & $1.58(0.45)$ & 0.058 \\
\hline & & Effect modification by GIK & & 0.535 \\
\hline
\end{tabular}


Table 3 (continued)

\begin{tabular}{|c|c|c|c|c|}
\hline Parameter & Start surgery & After GIK & End surgery & p-value \\
\hline \multicolumn{5}{|c|}{ Early lateral velocity $(\mathrm{cm} / \mathrm{s})$} \\
\hline All patients & $9.7(3.0)$ & $9.5(2.9)$ & $8.2(2.8)$ & $<0.001$ \\
\hline Placebo group & $10.1(3.0)$ & $9.4(2.7)$ & $7.0(2.3)$ & $<0.001$ \\
\hline \multirow[t]{2}{*}{ GIK group } & $9.4(3.0)$ & $9.5(3.1)$ & $9.2(2.8)$ & 0.660 \\
\hline & & Effect modification by GIK & & $<0.001$ \\
\hline \multicolumn{5}{|l|}{ E/e' ratio } \\
\hline All patients & $7.1(3.3)$ & $7.1(2.9)$ & $7.7(2.8)$ & 0.037 \\
\hline Placebo group & $6.8(2.1)$ & $6.8(2.0)$ & $8.2(2.6)$ & $<0.001$ \\
\hline \multirow[t]{2}{*}{ GIK group } & $7.3(4.0)$ & $7.4(3.5)$ & $7.1(2.8)$ & 0.735 \\
\hline & & Effect modification by GIK & & 0.001 \\
\hline \multicolumn{5}{|c|}{ Flow propagation velocity $(\mathrm{cm} / \mathrm{s})$} \\
\hline All patients & $39.3(8.8)$ & $39.6(6.1)$ & $39.2(7.9)$ & 0.793 \\
\hline Placebo group & $43.9(7.4)$ & $39.2(5.7)$ & $34.5(6.9)$ & $<0.001$ \\
\hline \multirow[t]{2}{*}{ GIK group } & $35.3(8.0)$ & $39.9(6.4)$ & $43.2(6.3)$ & $<0.001$ \\
\hline & & Effect modification by GIK & & $<0.001$ \\
\hline
\end{tabular}

Data given as mean (standard deviation)

Repeated-measures two-way analysis of variance (ANOVA) with Greenhouse-Geisser correction was used to estimate trend differences between and within group differences

$L V F A C$ left ventricular fractional area change, $3 D$ - $L V E F$ three-dimensional left ventricular ejection fraction, $2 D-L V E F$ two-dimensional left ventricular ejection fraction, $P G L S$ peak global longitudinal strain

myocardial ischemia $[12,35]$. In fasted animals, the oxidation of glucose, lactate and pyruvate contributes to less than $5 \%$ of myocardial energy production and has been associated with greater vulnerability to ischemic myocardial damages due to uncoupling of mitochondrial oxidative phosphorylation and energy dissipation [39]. In contrast, GIK infusion promotes a fed-liked state by altering gene expression and enzymes activities resulting in enhanced glucose uptake and glycogen synthesis with increased provision of high-energy substrates (ATP and creatinine phosphate) to sustain short period of myocardial ischemia. Indeed, experimental studies have reported an association between high pre-ischemic glycogen content and improved functional recovery from ischemia $[36,40]$.

Besides this glucose-dependent mechanism, insulin further protects the cardiomyocytes by activation of the phosphoinositide 3-kinase/protein kinase B (PI3K/Akt) pathway that regulates various signaling intracellular targets (e.g., endothelial nitric oxide synthase, mammalian target of rapamycine, forkhead transcription factors) and therefore minimizes apoptosis triggered by the ischemic insult [12, 41].

This study has some limitations. First, although both groups presented similar comorbidities and operative risk score, baseline GIK-treated patients presented lower LVEF than in the Placebo group, making them more sensitive to subsequent functional improvement. Second, TEE assessment was exclusively focused on the LV, using load-dependent indices of LV systolic function and mitral flow propagation velocity, a load-independent surrogate of LV relaxation. These investigation tools could also be applied to the RV which may benefit (or not) from GIK infusion. Third, this substudy was not designed nor powered to evaluate meaningful clinical outcomes. Hence, the observed improvement in LV function and reduced need for inotropes did not translate into reduced postoperative cardiac mortality and morbidity, except a reduced occurrence of pulmonary complications that was explained by easier weaning from the ventilator consequent to improved LV function. Interestingly, Duncan et al. recently reported that intraoperative maintenance of normoglycemia with a fixed high-dose insulin and variable glucose adjustment was associated with reduced 30-day mortality and morbidity after cardiac surgery [42].

In conclusion, we observed that the addition of GIK therapy to standard cardioprotective techniques in moderate-to-high risk patients with ischemic heart disease resulted in better preservation of LV systolic and diastolic function in the early period following separation from cardiopulmonary bypass. Further studies are required to warrant the long term clinical impact of improved functional recovery of the myocardium early after cardiac surgery. 
Systolic function

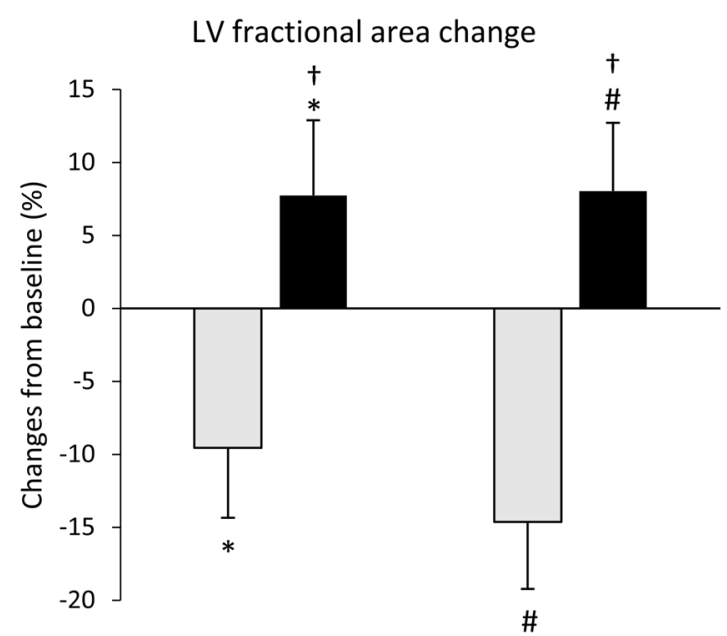

LVEF 3D measurement

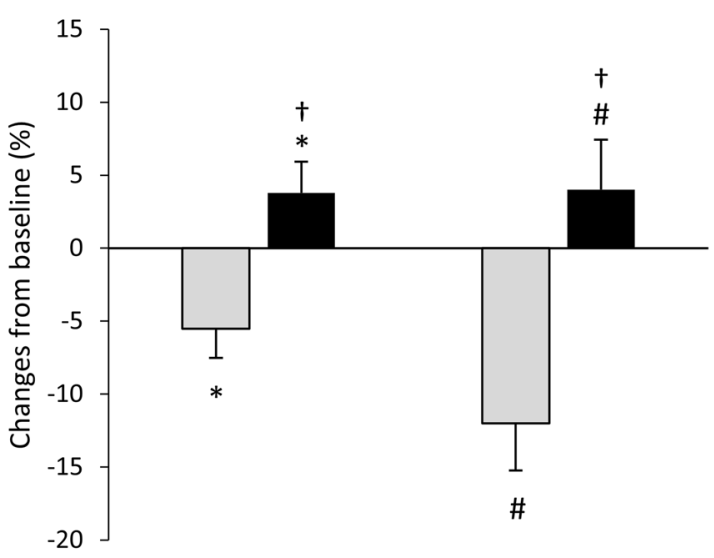

LVEF 2D measurement

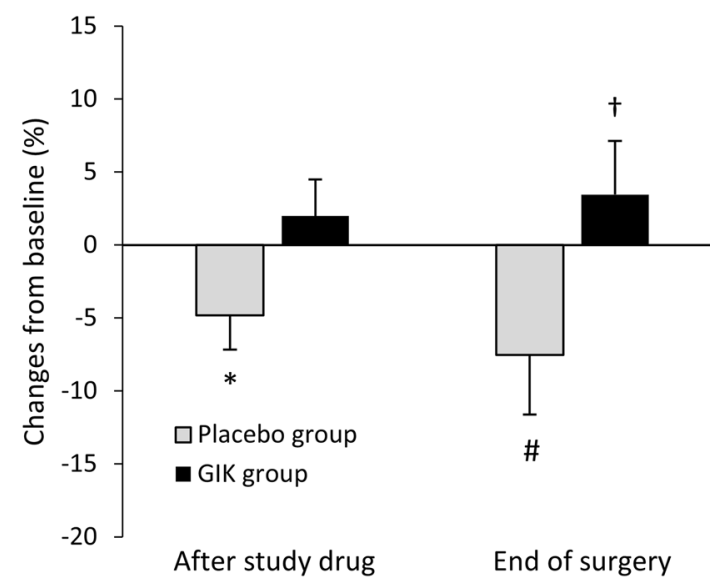

Fig. 3 Intraoperative changes in echocardiographic parameters occurring in patients undergoing CABG surgery. Data from 100 patients with complete high quality TEE exams (Placebo group $\mathrm{N}=46$; GIK

\section{Diastolic function}
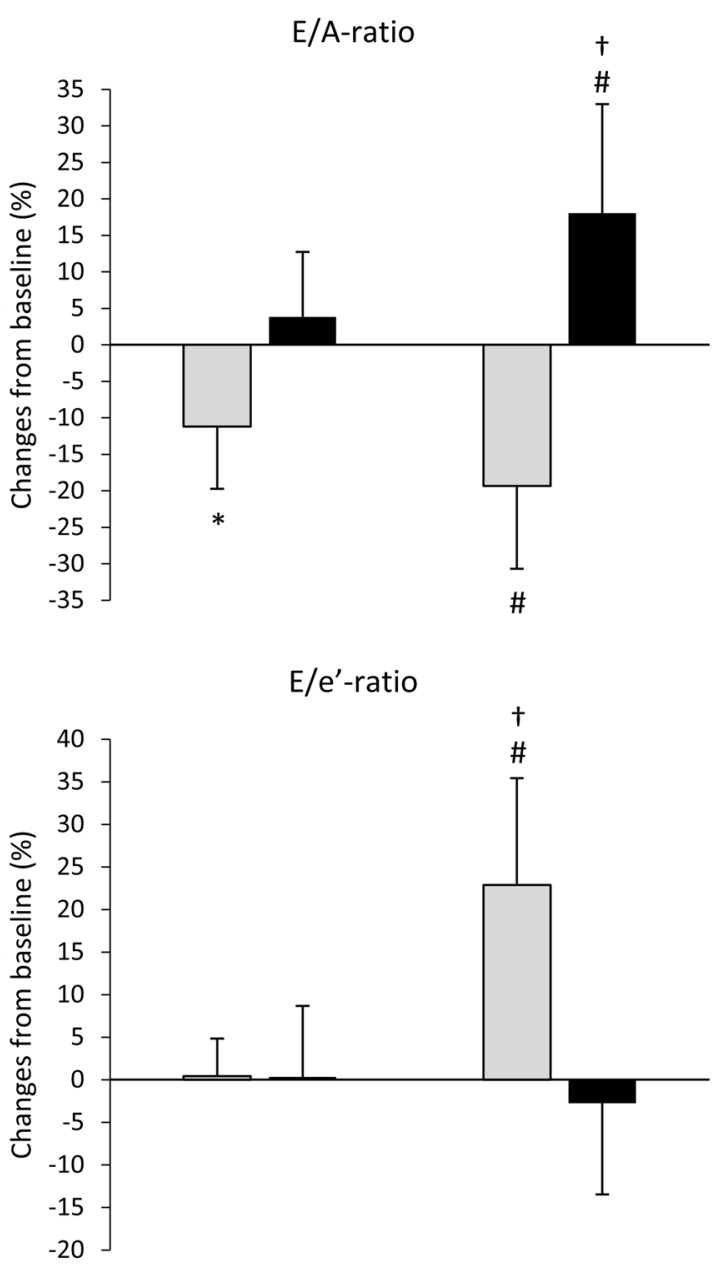

TM flow propagation velocity

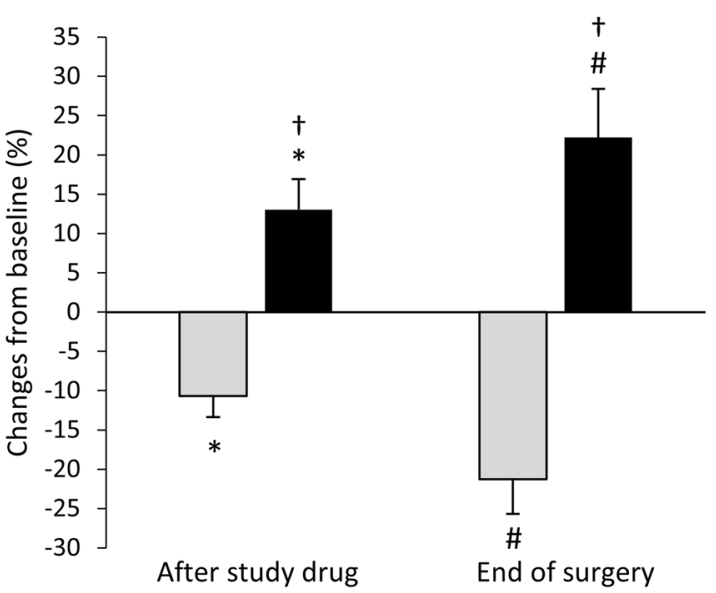

group $\mathrm{N}=54$ ). *Post-drug compared with baseline, $\mathrm{p}<0.05$; ${ }^{*}$ end of surgery compared with baseline, $\mathrm{p}<0.05$; ${ }^{\dagger} \mathrm{GIK}$ compared with Placebo, $\mathrm{p}<0.05$ 
Acknowledgements The authors acknowledge the patients, anaesthetists and operators who undertook the procedures, without whom the trial could not have happened.

Funding This is study was supported by the APSI Funds of the University Hospital of Geneva.

\section{Compliance with ethical standards}

Conflict of interest The authors have no conflict of interest to disclose.

\section{Fractional Area Change Placebo group}

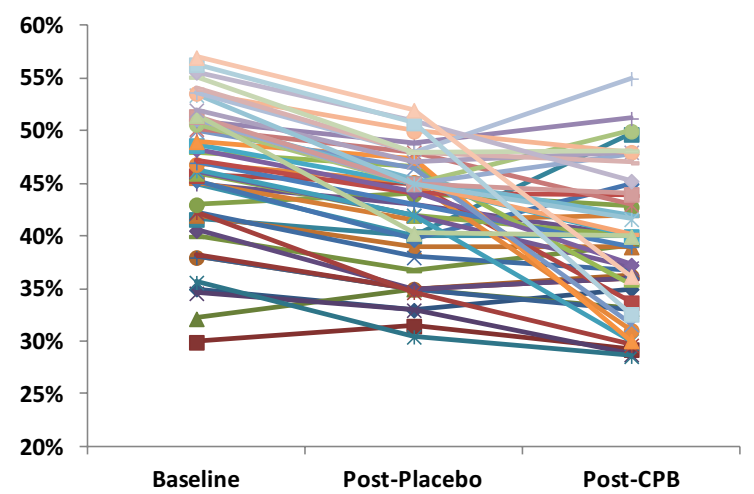

Ethics approval The trial was approved by the Ethics Committee of the University Hospital of Geneva (CER: 08-095) and was registered on the ClinicalTrials registry (NCT00788242; http://clinicaltrials.gov).

Informed consent All participants provided written informed consent in accordance with the Declaration of Helsinki.

\section{Appendix}

See Fig. 4 and Tables 4, 5.

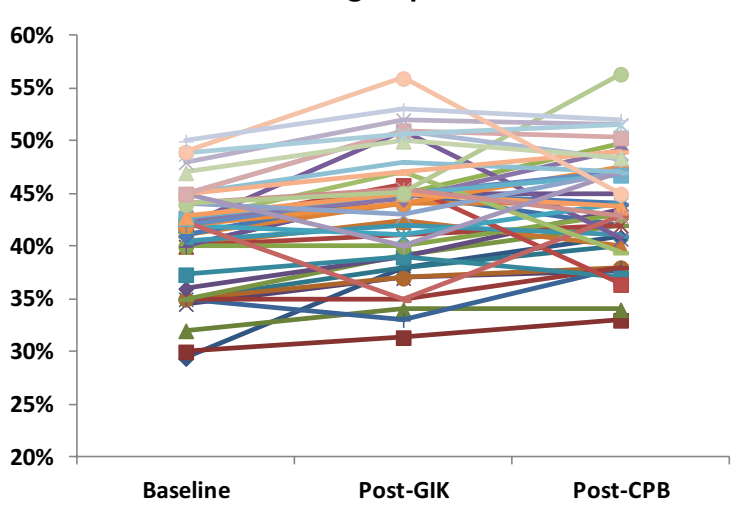

Fig. 4 Individual changes in fractional area changes (FAC) after drug infusion (Placebo or GIK) and after weaning from cardio-pulmonary bypass

Table 4 Grading of left ventricular diastolic function by echocardiography

\begin{tabular}{lccc}
\hline & Start of surgery & After GIK/placebo & End of surgery \\
\hline Normal & & & \\
Placebo $(\mathrm{N}=46)$ & $4(8.7)$ & $5(8.7)$ & $2(4.3)$ \\
GIK $(\mathrm{N}=54)$ & $5(9.2)$ & $10(18.4)$ & $8(14.8)$ \\
Grade I impaired relaxation & & & $18(43.9)$ \\
Placebo & $21(45.5)$ & $20(43.5)$ & $27(50.0)$ \\
GIK & $23(42.6)$ & $27(50.0)$ & $16(34.8)$ \\
Grade II pseudo-normalization & & & $14(25.9)$ \\
Placebo & $15(32.6)$ & $16(34.8)$ & $10(21.7)$ \\
GIK & $18(33.3)$ & $14(25.9)$ & $5(9.3)$ \\
Grade III restrictive pattern & & & $5(10.9)$ \\
Placebo & $6(13.0)$ & $3(5.5)$ & \\
GIK & $8(14.8)$ & & \\
\hline
\end{tabular}

Data given as number of patients (percentage)

Based on Nagueh et al. [20] 
Table 5 Clinical outcomes of patients undergoing coronary artery bypass grafting and receiving Placebo or glucoseinsulin potassium infusion

\begin{tabular}{|c|c|c|c|c|c|}
\hline Outcome & $\begin{array}{l}\text { Placebo } \\
(\mathrm{N}=46)\end{array}$ & $\begin{array}{l}\text { GIK } \\
(\mathrm{N}=54)\end{array}$ & $\mathrm{RR}$ & $(95 \% \mathrm{CI})$ & $\mathrm{p}$-value \\
\hline Mortality & $5(10.9)$ & $1(1.9)$ & 0.17 & $(0.02 ; 1.41)$ & $0.092 *$ \\
\hline Cardiovascular complications ${ }^{\mathrm{c}}$ & $25(54.4)$ & $25(46.3)$ & 0.85 & $(0.58 ; 1.23)$ & 0.422 \\
\hline Atrial fibrillation & $18(39.1)$ & $17(31.5)$ & 0.80 & $(0.47 ; 1.37)$ & 0.424 \\
\hline New/worsening heart failure & $9(19.6)$ & $4(7.4)$ & 0.38 & $(0.12 ; 1.15)$ & $0.083^{*}$ \\
\hline Myocardial infarct & $8(17.4)$ & $8(14.8)$ & 0.85 & $(0.35 ; 2.10)$ & 0.726 \\
\hline Stroke & $5(10.9)$ & $1(1.9)$ & 0.17 & $(0.02 ; 1.41)$ & $0.092 *$ \\
\hline Pulmonary complications ${ }^{\mathrm{d}}$ & $33(71.7)$ & $24(44.4)$ & 0.62 & $(0.44 ; 0.88)$ & 0.006 \\
\hline Atelectasis & $20(43.5)$ & $10(18.5)$ & 0.43 & $(0.22 ; 0.82)$ & 0.007 \\
\hline Pneumonia & $5(9.3)$ & $5(10.9)$ & 0.85 & $(0.26 ; 2.76)$ & 0.789 \\
\hline Ventilation $>24 \mathrm{~h}$ & $30(65.2)$ & $17(31.5)$ & 0.48 & $(0.31 ; 0.75)$ & 0.001 \\
\hline Renal dysfunction $^{\mathrm{e}}$ & $14(30.4)$ & $10(18.5)$ & 0.61 & $(0.30 ; 1.24)$ & 0.164 \\
\hline Troponin I $16-24 \mathrm{~h}$ post-surgery, $\mathrm{ng} / \mathrm{mL}^{\mathrm{a}}$ & $4.1(2.5 ; 7.9)$ & $3.5(1.9 ; 7.0)$ & $0.59^{\mathrm{b}}$ & $(-0.78 ; 1.86)$ & $0.354^{\#}$ \\
\hline
\end{tabular}

Data given as number (percentage) unless otherwise indicated. Chi-squared tests were used for statistical tests unless otherwise indicated

$R R$ risk ratio, $I C U$ intensive care unit

* Fisher exact test

"Wilcoxon rank sum test

${ }^{a}$ Data given as median (range)

${ }^{\mathrm{b}}$ Median difference

${ }^{\mathrm{c}}$ Composite including new or worsening LV failure, myocardial infarct, atrial fibrillation, and stroke

${ }^{\mathrm{d}}$ Composite including atelectasis, pneumonia, and mechanical ventilation $>24 \mathrm{~h}$

${ }^{\mathrm{e}}$ Increase in estimated glomerular filtration rate $>25 \%$

\section{References}

1. Writing Group M, Mozaffarian D, Benjamin EJ, et al. Heart disease and stroke statistics-2016 update: a report from the American Heart Association. Circulation. 2016;133:e38-60.

2. McNeely C, Markwell S, Vassileva C. Trends in patient characteristics and outcomes of coronary artery bypass grafting in the 2000 to 2012 medicare population. Ann Thorac Surg. 2016;102:132-8.

3. Blumenfeld O, Na'amnih W, Shapira-Daniels A, Lotan C, Shohat T. Shapira OM trends in coronary revascularization and ischemic heart disease-related mortality in Israel. J Am Heart Assoc 2017; 6:e004734.

4. ElBardissi AW, Aranki SF, Sheng S, O'Brien SM, Greenberg CC, Gammie JS. Trends in isolated coronary artery bypass grafting: an analysis of the Society of Thoracic Surgeons adult cardiac surgery database. J Thorac Cardiovasc Surg. 2012;143:273-81.

5. Likosky DS, Goldberg JB, DiScipio AW, et al. Variability in surgeons' perioperative practices may influence the incidence of lowoutput failure after coronary artery bypass grafting surgery. Circ Cardiovasc Qual Outcomes. 2012;5:638-44.

6. Nielsen DV, Hansen MK, Johnsen SP, Hansen M, Hindsholm K, Jakobsen CJ. Health outcomes with and without use of inotropic therapy in cardiac surgery: results of a propensity score-matched analysis. Anesthesiology. 2014;120:1098-108.

7. Lomivorotov VV, Efremov SM, Kirov MY, Fominskiy EV, Karaskov AM. Low-cardiac-output syndrome after cardiac surgery. J Cardiothorac Vasc Anesth. 2017;31:291-308.

8. Hausenloy DJ, Boston-Griffiths E, Yellon DM. Cardioprotection during cardiac surgery. Cardiovasc Res. 2012;94:253-65.
9. Dobson GP, Faggian G, Onorati F, Vinten-Johansen J. Hyperkalemic cardioplegia for adult and pediatric surgery: end of an era? Front Physiol. 2013;4:228.

10. Kunst G, Klein AA. Peri-operative anaesthetic myocardial preconditioning and protection-cellular mechanisms and clinical relevance in cardiac anaesthesia. Anaesthesia. 2015;70:467-82.

11. Cole SP, Gross ER. Happy 53rd birthday GIK: insulin, cake, and presents. Anesthesiology. 2015;123:249-50.

12. Ng KW, Allen ML, Desai A, Macrae D, Pathan N. Cardioprotective effects of insulin: how intensive insulin therapy may benefit cardiac surgery patients. Circulation. 2012;125:721-8.

13. Fan Y, Zhang AM, Xiao YB, Weng YG. Hetzer R Glucose-insulin-potassium therapy in adult patients undergoing cardiac surgery: a meta-analysis. Eur J Cardiothorac Surg. 2011;40:192-9.

14. Ali-Hassan-Sayegh S, Mirhosseini SJ, Zeriouh M, et al. Safety and efficacy of glucose-insulin-potassium treatment in coronary artery bypass graft surgery and percutaneous coronary intervention. Interact Cardiovasc Thorac Surg. 2015;21:667-76.

15. Ellenberger C, Sologashvili T, Kreienbuhl L, Cikirikcioglu M, Diaper J, Licker M. Myocardial protection by glucose-insulinpotassium in moderate- to high-risk patients undergoing elective on-pump cardiac surgery: a randomized controlled trial. Anesth Analg. 2018;126:1133-41.

16. Ellenberger C, Sologashvili T, Bhaskaran K, Licker M. Impact of intrathecal morphine analgesia on the incidence of pulmonary complications after cardiac surgery: a single center propensitymatched cohort study. BMC Anesthesiol. 2017;17:109.

17. Licker M, Diaper J, Cartier V, et al. Clinical review: management of weaning from cardiopulmonary bypass after cardiac surgery. Ann Card Anaesth. 2012;15:206-23.

18. Lang RM, Bierig M, Devereux RB, et al. Recommendations for chamber quantification: a report from the American Society of 
Echocardiography's Guidelines and Standards Committee and the Chamber Quantification Writing Group, developed in conjunction with the European Association of Echocardiography, a branch of the European Society of Cardiology. J Am Soc Echocardiogr. 2005;18:1440-63.

19. Nagueh SF, Appleton CP, Gillebert TC, et al. Recommendations for the evaluation of left ventricular diastolic function by echocardiography. J Am Soc Echocardiogr. 2009;22:107-13.

20. Nagueh SF, et al. Recommendations for the evaluation of left ventricular diastolic function by echocardiography: an update from the American Society of Echocardiography and the European Association of cardiovascular imaging. Am Soc Echocardiogr. 2016;29:277-314.

21. Ding W, Ji Q, Shi Y, Ma R. Predictors of low cardiac output syndrome after isolated coronary artery bypass grafting. Int Heart $\mathrm{J}$. 2015;56:144-9.

22. Berman M, Stamler A, Sahar G, et al. Validation of the 2000 Bernstein-Parsonnet score versus the EuroSCORE as a prognostic tool in cardiac surgery. Ann Thorac Surg. 2006;81:537-40.

23. Chakravarthy M. Quality in cardiac anesthesia: is there an alternative to its practice? Ann Card Anaesth. 2015;18:130-2.

24. Grossgasteiger M, Hien MD, Graser B, et al. Assessment of left ventricular size and function during cardiac surgery. An intraoperative evaluation of six two-dimensional echocardiographic methods with real time three-dimensional echocardiography as a reference. Echocardiography. 2013;30:672-81.

25. Pouleur AC, le Polain de Waroux JB, Pasquet A, et al. Assessment of left ventricular mass and volumes by three-dimensional echocardiography in patients with or without wall motion abnormalities: comparison against cine magnetic resonance imaging. Heart. 2008;94:1050-7.

26. Ma C, Chen J, Yang J, et al. Quantitative assessment of left ventricular function by 3-dimensional speckle-tracking echocardiography in patients with chronic heart failure: a meta-analysis. J Ultrasound Med. 2014;33:287-95.

27. Yang HS, Song BG, Kim JY, Kim SN, Kim TY. Impact of propofol anesthesia induction on cardiac function in low-risk patients as measured by intraoperative Doppler tissue imaging. J Am Soc Echocardiogr. 2013;26:727-35.

28. Nishikawa K, Kanaya N, Kawamata M, Namiki A. Left ventricular mechanical performance in elderly patients after induction of anaesthesia. A comparison of inhalational induction with sevoflurane and intravenous induction with fentanyl and propofol. Anaesthesia. 2004;59:948-53.

29. Nicolas-Robin A, Amour J, Ibanez-Esteve C, Coriat P, Riou B, Langeron O. Effect of glucose-insulin-potassium in severe acute heart failure after brain death. Crit Care Med. 2008;36:2740-5.

30. Di Marco S, Boldrini B, Conti U, et al. Effects of GIK (glucoseinsulin-potassium) on stress-induced myocardial ischaemia. Clin Sci. 2010;119:37-44.
31. Grossman AN, Opie LH, Beshansky JR, Ingwall JS, Rackley CE. Selker HP glucose-insulin-potassium revived: current status in acute coronary syndromes and the energy-depleted heart. Circulation. 2013;127:1040-8.

32. Chanda D, Luiken JJ, Glatz JF. Signaling pathways involved in cardiac energy metabolism. FEBS Lett. 2016;590:2364-74.

33. Ranasinghe AM, McCabe CJ, Quinn DW, et al. How does glucose insulin potassium improve hemodynamic performance? Evidence for altered expression of beta-adrenoreceptor and calcium handling genes. Circulation. 2006;114:I239-44.

34. Ferrara N, Abete P, Corbi G, et al. Insulin-induced changes in beta-adrenergic response: an experimental study in the isolated rat papillary muscle. Am J Hypertens. 2005;18:348-53.

35. von Lewinski D, Bruns S, Walther S, Kogler H, Pieske B. Insulin causes $\left[\mathrm{Ca}^{2+}\right] \mathrm{i}$-dependent and $\left[\mathrm{Ca}^{2+}\right] \mathrm{i}$-independent positive inotropic effects in failing human myocardium. Circulation. 2005;111:2588-95.

36. Albacker T, Carvalho G, Schricker T, Lachapelle K. High-dose insulin therapy attenuates systemic inflammatory response in coronary artery bypass grafting patients. Ann Thorac Surg. 2008;86:20-7.

37. Klein LJ, Visser FC. The effect of insulin on the heart: Part 2: effects on function during and post myocardial ischaemia. Neth Heart J. 2010;18:255-9.

38. Cottin Y, Lhuillier I, Gilson L, et al. Glucose insulin potassium infusion improves systolic function in patients with chronic ischemic cardiomyopathy. Eur J Heart Fail. 2002;4:181-4.

39. Liepinsh E, Makrecka M, Kuka J, et al. The heart is better protected against myocardial infarction in the fed state compared to the fasted state. Metabolism. 2014;63:127-36.

40. Cross HR, Opie LH, Radda GK, Clarke K. Is a high glycogen content beneficial or detrimental to the ischemic rat heart? A controversy resolved. Circ Res. 1996;78:482-91.

41. Yao H, Han X, Han X. The cardioprotection of the insulin-mediated PI3K/Akt/mTOR signaling pathway. Am J Cardiovasc Drugs. 2014;14:433-42.

42. Duncan AE, Sessler DI, Sato H, et al. Hyperinsulinemic normoglycemia during cardiac surgery reduces a composite of 30-day mortality and serious in-hospital complications: a randomized clinical trial. Anesthesiology. 2018;128:1125-39.

Publisher's Note Springer Nature remains neutral with regard to jurisdictional claims in published maps and institutional affiliations. 